\title{
Physical properties of some Sn-based melts
}

\author{
Valeriy Sidorov ${ }^{1}$, Sergej Uporov ${ }^{1}$, Elena Rozitsina ${ }^{1}$, Denis Yagodin $^{1}$, Kirill Grushevskij $^{1}$ and Nina Ilinykh ${ }^{2}$ \\ ${ }^{1}$ Ural State Pedagogical University, 620017 Ekaterinburg, Russia, sidorov@uspu.ru \\ ${ }^{2}$ Ural Technical Institute of Telecommunications and Informatics, 15 Repin Str.Ekaterinburg, Russia
}

\begin{abstract}
The physical properties (viscosity, density, electroresistivity and magnetic susceptibility) of pure tin, copper, silver, some binary $(\mathrm{Sn}-\mathrm{Ag}, \mathrm{Sn}-\mathrm{Cu}, \mathrm{Sn}-\mathrm{Bi}, \mathrm{Sn}-\mathrm{Zn})$ and ternary $(\mathrm{Sn}-\mathrm{Ag}-\mathrm{Cu}, \mathrm{Sn}-\mathrm{Bi}-$ $\mathrm{Ag}, \mathrm{Sn}-\mathrm{Bi}-\mathrm{Zn}$ ) alloys with near eutectic compositions are investigated in wide temperature ranges. The irreversible decrease of viscosity in pure tin melt is discovered at $820^{\circ} \mathrm{C}$ during heating. The similar anomaly with the following hysteresis of dynamic viscosity was fixed for binary and ternary alloys but at higher temperatures $-900^{\circ} \mathrm{C}$ and $950^{\circ} \mathrm{C}$ respectively. For all the systems it was shown that the alloys with eutectic compositions differ significantly in their electric and magnetic properties from hypo- and hypereutectic ones. Qualitative and quantitative metallographic analysis for $\mathrm{Sn}-3.8 \mathrm{wt} . \% \mathrm{Ag}-0.7 \mathrm{wt} . \% \mathrm{Cu}$ samples, heated low and above characteristic temperatures, showed the influence of melt overheating on crystallization kinetics.
\end{abstract}

\section{Introduction.}

Because of the toxicity of lead, traditional $\mathrm{Sn}-\mathrm{Pb}$ solders are now being replaced with Sn-base soldering alloys containing additions of other metals (Ag, Bi, $\mathrm{Zn}$ etc.), see, for example, [1-5]. In Europe the extensive search for new lead-free soldering materials is now coordinated by COST Action MP0602 till 2011. However, physical properties of these new solders at high temperatures, especially in liquid state, are practically unknown.

In this paper we present experimental results on density (obtained by gamma-penetration method), viscosity (by torsion oscillation method), electroresistivity (by contactless method in rotating magnetic field) and magnetic susceptibility (by Faraday's method) for pure liquid tin, copper and silver, some binary (Sn-Ag, Sn-Cu, Sn-Bi, Sn-Zn) and ternary (Sn-Ag-Cu, Sn-Bi-Ag, Sn-Bi-Zn) alloys with near eutectic compositions in wide temperature ranges.

\section{Results.}

The temperature curves of properties are found to be smooth in cases of liquid copper and silver. It means that no sharp structural changes take place in these melts during heating and the following cooling.

As for liquid tin of commercial purity $99.9 \%$, three temperature ranges with abnormal behavior of properties were discovered: $t_{1}$ near $400^{\circ} \mathrm{C}$ (anomalies in density and electroresistivity); $t_{2}=900-1000^{\circ} \mathrm{C}$ (anomalies in viscosity and electroresistivity); $\mathrm{t}_{3}$ approx. $1400^{\circ} \mathrm{C}$ (anomalies in density, electroresistivity and magnetic susceptibility).

For example, the typical temperature dependence of viscosity for pure liquid tin $(99.999 \%)$, obtained during heating and the following cooling with the rate of $1 \mathrm{~K} / \mathrm{min}$, is shown at fig. 1 . One can see the drastic $(12 \%)$ irreversible decrease of viscosity at $820^{\circ} \mathrm{C}$ during heating. Below this temperature the cooling curve differs from the heating one till the beginning of crystallization - the hysteresis of property takes place. Let us mention, that this branching point does not correspond to melting temperatures of $\mathrm{SnO}$ and $\mathrm{SnO}_{2}$ oxides $\left(1080^{\circ} \mathrm{C}\right.$ and $1127^{\circ} \mathrm{C}$ respectively) that can exist in the melt. The increase in heating rate to 4 $\mathrm{K} / \mathrm{min}$ shifts the temperature of anomaly - it can reach $1000^{\circ} \mathrm{C}$. Moreover, the decrease in purity of samples (from $99.999 \%$ to $99.9 \%$ ) provides the appearance of hysteresis in limited temperature interval only, for all $\mathrm{t}<600^{\circ} \mathrm{C}$ heating and cooling curves coincide. If the heating temperature does not overcome $800^{\circ} \mathrm{C}$, than heating and cooling curves demonstrate smooth behavior and coincide in all investigated range.

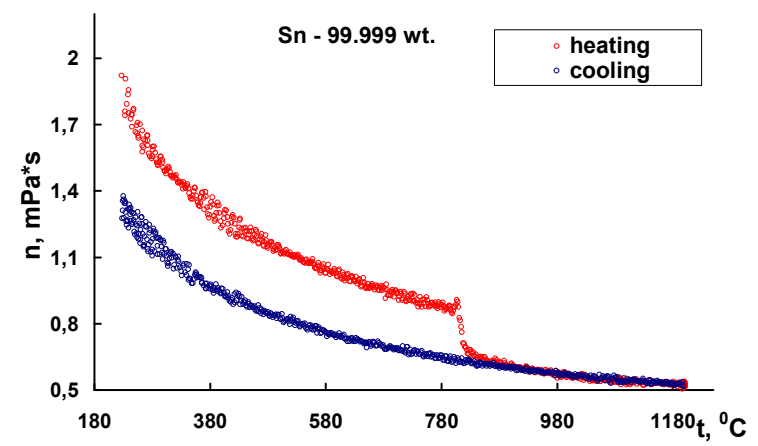

Fig.1. Dynamic viscosity of pure liquid tin vs temperature.

The similar results were obtained for $\mathrm{Sn}-\mathrm{Cu}$ melts of commercial purity. We investigated kinematic viscosity of liquid tin, containing $0.5 ; 0.7$ and 1.0 wt. $\%$ of copper. For binary melt Sn- 0.5 wt. $\%$ $\mathrm{Cu}$ the abnormal behavior of viscosity (jump down) was found at $t_{1}=790^{\circ} \mathrm{C}$. At subsequent cooling the hysteresis of heating and cooling curves appears above $700^{\circ} \mathrm{C}$ only. The variations in the highest temperature of the experiment give the following: when the melt is heated to $700^{\circ} \mathrm{C}$ only, the heating

This is an Open Access article distributed under the terms of the Creative Commons Attribution-Noncommercial License 3.0, which permits unrestricted use, distribution, and reproduction in any noncommercial medium, provided the original work is properly cited. 
and cooling curves are smooth, no anomalies and hysteresis are fixed. If the melt is overheated to $1000^{\circ}$ $\mathrm{C}$, the mentioned anomaly takes place at $790^{\circ} \mathrm{C}$ and hysteresis exists from that temperature till $700^{\circ} \mathrm{C}$. The additional scans with used or fresh samples to $1250^{\circ} \mathrm{C}$ and to $1500^{\circ} \mathrm{C}$ do not bring any changes in the situation - it looks as described above, with hysteresis in limited temperature range.

From the data of magnetic susceptibility measurements it comes that at the discussed temperature $790^{\circ} \mathrm{C}$ the melt transforms from paramagnetic to diamagnetic state. Starting from this temperature the cooling curve at reverse scan differs from the heating one - the melt remains diamagnetic till crystallization.

Thus the investigations of kinematic viscosity and magnetic susceptibility proved the fact that the addition of $0.5 \mathrm{wt}$. \% of copper into liquid tin decrease the temperature of anomaly (possible structural rearrangement) to $790^{\circ} \mathrm{C}$. However this temperature is still rather high to be used in technology of lead-free solders production.

The enlargement of copper content gives the following: for $\mathrm{Sn}-0.7 \quad \mathrm{wt} . \% \mathrm{Cu}$ alloy the transformation temperature shifts down for $20^{\circ} \mathrm{C}$; as for $\mathrm{Sn}-1.0 \mathrm{wt} . \% \mathrm{Cu}$ alloy it increases for $20^{\circ} \mathrm{C}$ and reaches $810^{\circ} \mathrm{C}$. Hence, from practical point of view the eutectic Sn-0.7 wt.\% Cu composition can be considered as the most perspective one for applying new heat treatment regimes of melt preparation before solidification.

The additional investigations of dynamic viscosity for three eutectic compositions in $\mathrm{Sn}-\mathrm{Cu}-\mathrm{Ag}$ system (Sn-3,8wt.\%Ag-0,7wt.\%Cu, Sn-20wt.\%Ag$5,7 \mathrm{wt} . \% \mathrm{Cu}$ and $\mathrm{Sn}-38,77 \mathrm{wt} . \% \mathrm{Ag}-8,54 \mathrm{wt} . \% \mathrm{Cu}$ ), prepared from the elements of high purity, were carried out. It was stated that the enlargement of doped elements cause the increase in viscosity absolute values. At the same time the temperature of anomaly and branching point shifts to $960-970^{\circ} \mathrm{C}$ with the increasing of hysteresis value (fig.2).

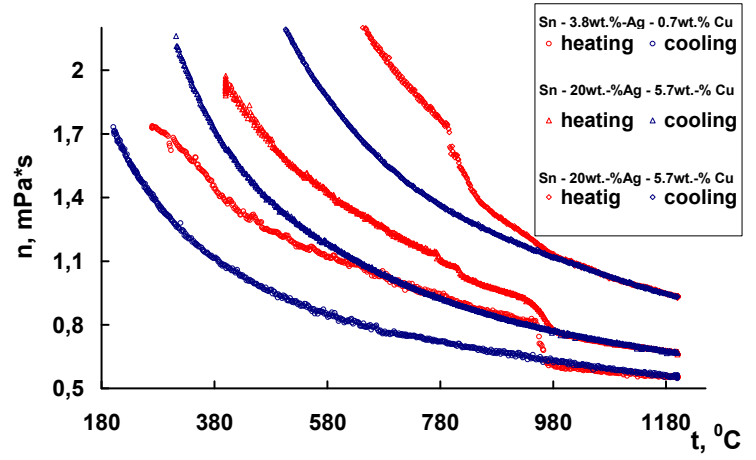

Fig.2. The temperature dependences of dynamic viscosity for three eutectic $\mathrm{Sn}-\mathrm{Ag}-\mathrm{Cu}$ melts.

Further on in order to point out the influence of melt state on structure of solidified metal, the qualitative and quantitative metallographic analysis for $\mathrm{Sn}-3.8 \mathrm{wt} . \% \mathrm{Ag}-0.7 \mathrm{wt} . \% \mathrm{Cu}$ samples, heated low and above characteristic temperatures, was done using REM Quanta 200 (fig. 3 and 4). It was found that microstructure of the sample heated to $680^{\circ} \mathrm{C}$ is ternary eutectic consisting of $\varepsilon\left(\mathrm{Ag}_{3} \mathrm{Sn}\right), \mathrm{Sn}$ and $\eta\left(\mathrm{Cu}_{6} \mathrm{Sn}_{5}\right)$ phases with plate-needle morphology and regions of fan splitting. The matrix is tin, the needles are $\varepsilon$-phase and separated small crystals of irregular shape $-\eta$-phase. There are several pseudo primary crystals of $\varepsilon$-phase also and they play the role of nucleation centers for eutectic crystals with the same stoichiometry.

The microstructure of the sample heated to $1200^{\circ} \mathrm{C}$ has the same structural components, but there are some differences as well. The main is that the alloy becomes hypoeutectic. It has primary $\varepsilon$ phase in the form of long plates and crystals with face morphology and ternary eutectic $\left[\varepsilon\left(\mathrm{Ag}_{3} \mathrm{Sn}\right)+\mathrm{Sn}+\eta\left(\mathrm{Cu}_{6} \mathrm{Sn}_{5}\right)\right]$ in the form of large plates with regions of fan splitting. Thus, for this composition overheating the melt influences on crystallization kinetics - the latest goes according to metastable diagram and is describing by "shifting" of the eutectic point to high melting element silver. At the same time, elements redistribution inside phases was not found. By using heat treatment of the melt it becomes possible to increase silver content in the solution and hence to improve wetting characteristics of the alloy. By using heat treatment of the melt it becomes possible to increase silver content in the solution and hence to improve wetting characteristics of the alloy.

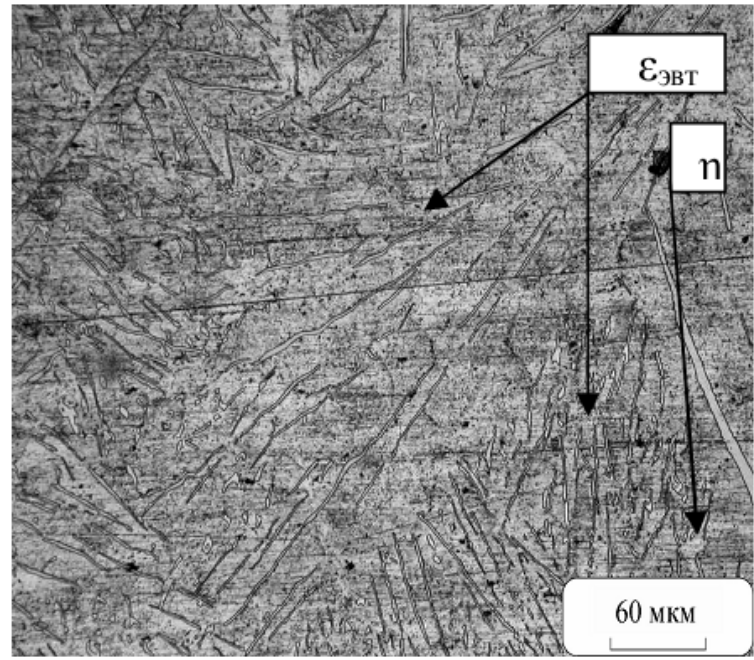

Fig.3. The metallographic analysis for $\mathrm{Sn}$ 3.8wt.\%Ag-0.7wt.\%Cu samples heated up to $681{ }^{\circ} \mathrm{C}$.

In this work we studied temperature dependences of density, electroresistivity and magnetic susceptibility of $\mathrm{Sn}-\mathrm{Bi}$ alloys. All the experiments were performed during heating up to $1000-1100^{\circ} \mathrm{C}$ and subsequent cooling in helium atmosphere with the step $10-20^{\circ}$ and isothermal expositions for 5-20 min at each temperature. Three compositions, containing 37, 42 (eutectic) and $47 \mathrm{wt}$. $\%$ of tin, were investigated.

Density temperature curves were found to be linear, whereas density absolute values increase with the enlargement of bismuth content (fig.5). However, the positive deviation from Raul's law was 
discovered and this is an evidence of predominant interaction between similar atoms in the melts.

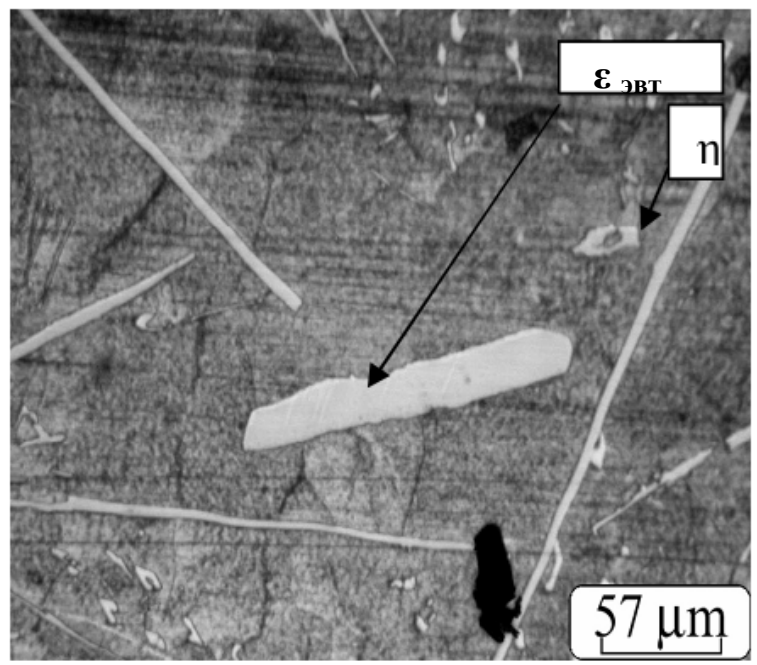

Fig.4. The metallographic analysis for $\mathrm{Sn}$ $3.8 \mathrm{wt} . \% \mathrm{Ag}-0.7 \mathrm{wt} . \% \mathrm{Cu}$ samples heated up to 1200 ${ }^{0} \mathrm{C}$.

From electroresistivity temperature curves it comes that this property depends on bismuth content greatly, especially near melting interval. We would like to point out semi-conductor behavior of the resistivity below $220^{\circ} \mathrm{C}$ found for liquid alloys with 37 and 42 wt. $\%$ of tin. The alloy with eutectic composition has the biggest temperature coefficient of resistivity in liquid state.

The results on magnetic susceptibility show that Bi37 wt. \% Sn and Bi-47 wt. \% Sn alloys remain diamagnetic in all investigated temperature range, whereas $\mathrm{Bi}-42$ wt. \% Sn alloy becomes paramagnetic above $250^{\circ} \mathrm{C}$.

Comparing the results one can see that the alloy with eutectic composition Bi-42 wt. \% Sn differs in electronic structure from hypo- and hypereutectic alloys. However, for all the compositions it was found that overheating the melts above characteristic temperature leads to the appearance of hysteresis (noncoincidence of heating and cooling curves in solid state) in properties sensitive to electronic structure (electroresistivity and magnetic susceptibility).

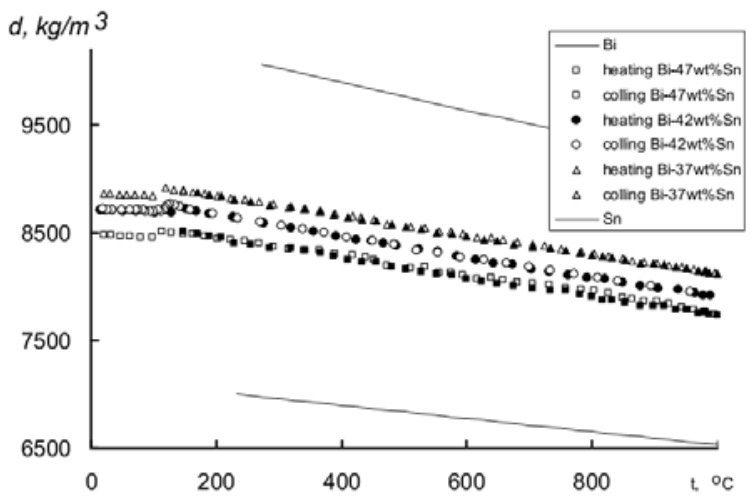

Fig.5. Density temperature curves for Sn-Bi alloys.
Temperature dependences of density, electroresistivity and magnetic susceptibility of SnAg alloys were studied as well. The investigated samples contained 3, 3.5 (eutectic) and 4 wt. \% of silver. The experimental conditions were similar to those described above.

It was found that density temperature dependences are linear for all the compositions, no hysteresis was fixed. As in case of Sn-Bi melts, the positive deviation from Raul's law was discovered, and this is an evidence of predominant interaction between similar atoms in the melts.

Electroresistivity absolute values were obtained to be independent on chemical content of the samples in solid state, whereas in liquid phase the eutectic alloy has the biggest $\rho$. It is necessary to mention the existence of curve $\rho(T)$ bend near $850^{\circ} \mathrm{C}$, which demonstrates the changes in electronic structure of melt (fig.6).

Sn-Ag alloys we discovered to be very poor magnetic materials and we got rather big random spread of experimental points. Nevertheless, it is possible to outline that magnetic susceptibility practically does not depend on composition in liquid state, but in solid state the highest $\chi$ values has $\mathrm{Sn}-3.5$ wt. \% Ag alloy.

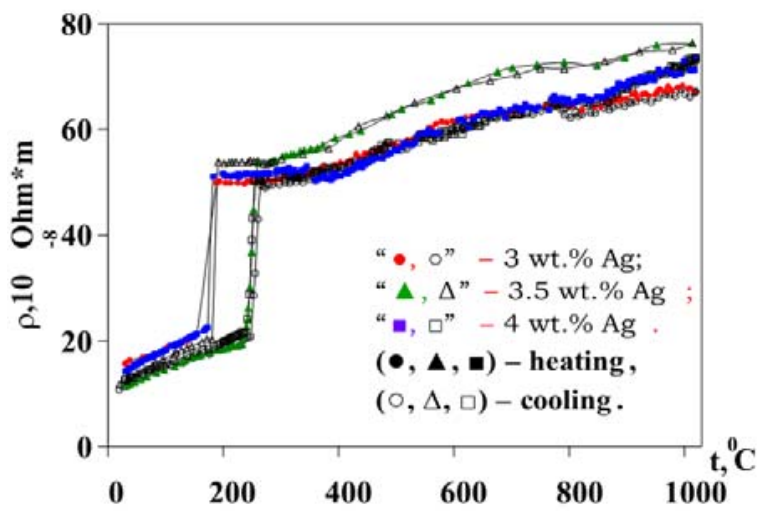

Fig.6. Electroresistivity temperature curves for $\mathrm{Sn}-\mathrm{Ag}$ alloys.

In the work we investigated also density, electroresistivity and magnetic susceptibility of Sn$\mathrm{Zn}$ alloys, containing 5.5; 8.5 (eutectic) and $10.5 \mathrm{wt}$. $\%$ of zinc. Due to high vapor tension of zinc, the samples were preliminary smelted and analyzed on chemical content. The experiments were performed in sealed crucibles, using conditions described above.

The density temperature curves have linear form both in solid and liquid states, no hysteresis was found. The dependence of molar volume vs zinc content practically follows Raul's law, i.e. Sn-Zn alloys can be considered as ideal solutions.

As in case of density, resistivity temperature curves were found to be linear both in solid and liquid states, no hysteresis was fixed, except for crystallization interval where undercooling for $30-50^{\circ}$ was obtained. The alloy with eutectic composition differs from others again: it has the highest resistivity 
values and maximal temperature coefficient of resistivity.

The magnetic studies of $\mathrm{Sn}-\mathrm{Zn}$ alloys showed that susceptibility of liquid Sn-5.5 wt. \% Zn and $\mathrm{Sn}-10.5$ wt. \% $\mathrm{Zn}$ alloys is negative and practically does not differ from susceptibility of pure tin. Eutectic composition $\mathrm{Sn}-8.5$ wt. \% $\mathrm{Zn}$ remains paramagnetic in investigated temperature range and is characterized by rather big $\chi$ values. No hysteresis of susceptibility was fixed, heating and cooling curves coincide within uncertainty of the experiment (fig.7).

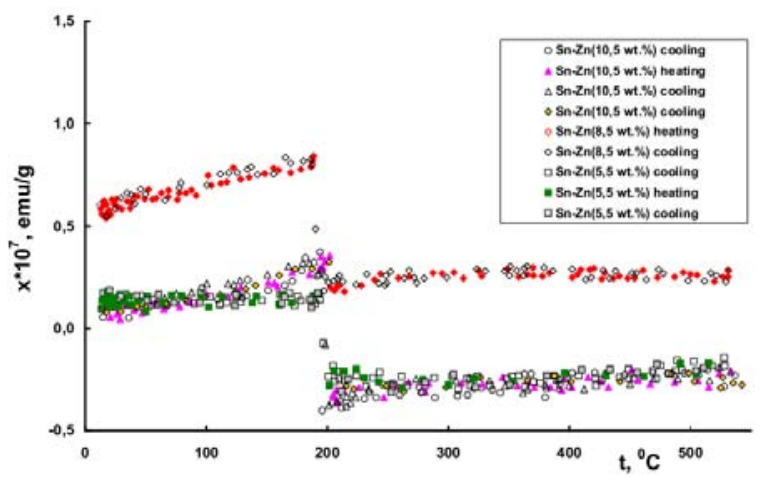

Fig.7. Magnetic susceptibility temperature curves for $\mathrm{Sn}-\mathrm{Zn}$ alloys.

Besides of binary alloys we studied density and magnetic susceptibility of ternary $\mathrm{Sn}-\mathrm{Bi}-\mathrm{Ag}(0.5$; 1.0 (eutectic) and $1.5 \mathrm{wt} . \%$ of silver) and $\mathrm{Sn}-\mathrm{Bi}-\mathrm{Zn}$ $(0.5 ; 1.0 ; 1.5$ (eutectic) and 3.0 wt. \% of zinc) alloys with near eutectic (Bi-42 wt. \% Sn) compositions.

All the alloys are characterized by abnormal melting (density increases while melting) and it is less pronounced for eutectic compositions. We connect this fact with high content of bismuth in the alloys.

The density temperature curves were found to be smooth in liquid state; no anomalies and hysteresis were fixed. The variations in silver or zinc content provide only small changes in density absolute values and do not influence on curves shape (fig.8).

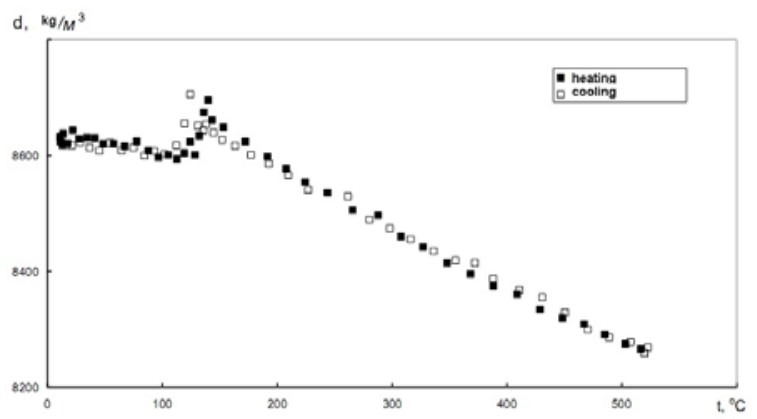

Fig.8. Density temperature dependence for $\mathrm{Sn}-58$ wt.\% Bi-1.5 wt. \%Zn alloy.

Magnetic properties of Sn-Bi-Ag compositions are determined mainly by magnetic properties of bismuth: in solid state the alloys are diamagnetic, whereas in liquid hypo- and hyper eutectic alloys become paramagnetic, but the alloy with 1.0 wt. $\%$ of silver remains diamagnetic.

Overheating the melts above $600^{\circ} \mathrm{C}$ causes the noncoincidence of heating and cooling curves below $400^{\circ} \mathrm{C}$ - the cooling curve is higher than the heating one. The hysteresis of property takes place for all the alloys in solid state and for eutectic alloy it is the biggest one.

The similar results in magnetic properties were obtained for $\mathrm{Sn}-\mathrm{Bi}-\mathrm{Zn}$ alloys also. Overheating the melts above $600^{\circ} \mathrm{C}$ provides the hysteresis of property in solid state (the cooling curve is higher than the heating one) and for eutectic composition it is the biggest one (fig.9).

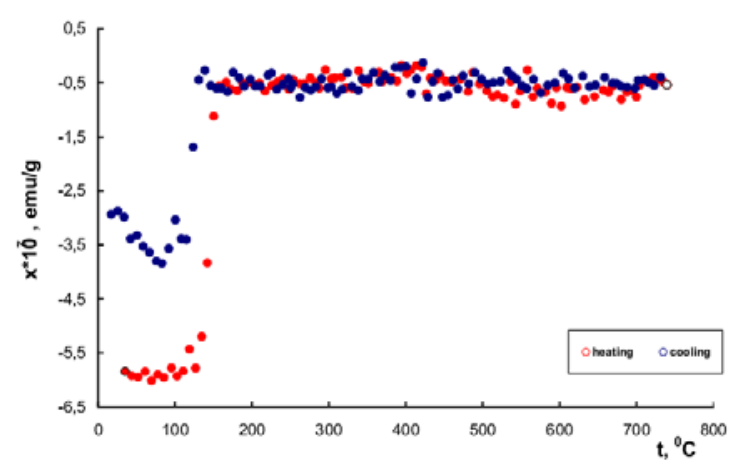

Fig.9. Magnetic susceptibility temperature dependence for Sn-58 wt.\% Bi-1.5 wt.\%Zn alloy.

\section{Discussion.}

The question about structural transformations in liquid tin in the range $700-1000^{\circ} \mathrm{C}$ is in discussion for a long time. Let us mention here rather old publication of Goryaga [6] and rather fresh one of Itami et al [7].

From our point of view, the jumping decrease of viscosity at $820^{\circ} \mathrm{C}$ can be connected with the loss of short-range ordering (SRO) in pure liquid tin. Our estimations, made in [8], showed that starting from the this temperature tin melt cannot be described by single SRO and atoms spatial distribution can be given as random close packing of hard spheres. The presence of impurities (in the first place - oxygen) strongly affects both the position and size of the anomaly. Therefore, the temperature of the anomalous changes in properties varies in different works and in some papers the curves are smooth. The high temperature (structureless) melt state can be conserved for a long time even at $\mathrm{t}<\mathrm{t}_{\mathrm{an}}$ due to several reasons. Firstly, the appearance by fluctuation of microregions (clusters) with the SRO, similar to the solid state before melting, requires enormous time. Secondly, the loss of SRO in the melt provides the unlimited solubility of doped elements in it and hence uniform volume distribution of different atoms (when the melt is characterized by SRO only the limited amount of the second element can be dissolute in it). That is why the cooling curve of property (viscosity in our case) can differ from the heating one in the conditions of real experiment, and this fact was fixed in our experiments. 


\section{Conclusions.}

The new experimental data on density, electroresistivity and magnetic susceptibility for some binary ( $\mathrm{Sn}-\mathrm{Bi}, \mathrm{Sn}-\mathrm{Ag}$ and $\mathrm{Sn}-\mathrm{Zn})$ and ternary (Sn-Bi-Ag and Sn-Bi-Zn) alloys with near eutectic compositions are obtained in wide temperature ranges. The alloys with eutectic content of elements were found to differ significantly from hypo- and hypereutectic ones in electric and magnetic properties. The temperature interval, overheating above which leads to the appearance of hysteresis of properties in solid state, was discovered. If one use the metals of high purity as initial components, than the temperature of hysteresis is in the range $800-900^{\circ}$ $\mathrm{C}$, when the metals of commercial purity are used, the branching point of heating and cooling curves shifts down to $400^{\circ} \mathrm{C}$. We have all grounds to think that application of different regimes of melt heattreatment can bring significant changes in properties of solid lead-free solders and joints.

\section{References.}

1. M.O. Alam, Y.C. Chan, K.N. Tu, J. Appl. Phys. 94, 4108 (2003).

2. M.Y. Chiu, S.S. Wang, T.H.Chuang, J. Electronic Mater. 31, 494 (2002).

3. Jeong-Won Yoon, Sang-Won Kim, Ja-Myeoung Koo, Dae-Gon Kim, Seoung-Boo Jung, J. Electronic Mater. 33, 1190 (2004).

4. Hwa-Teng Lee, Heng-Sheng Lin, Cheng-Shyan Lee, Po-Wei Chen, Mater. Sci. Eng. A, 407, 36 (2005).

5. M.J. Rizvi, Y.C. Chan, C, Bailey, H. Lu, M.N. Islam, J. Alloys Comp. 407, 208 (2006).

6. G.I. Goryaga, Vestnik MGU, 1, 133 (1950) (in Russian).

7. T. Itami, S. Munejiri, T. Masaki, Rhys. Rev. B, 67, 064201 (2003)

8. V.E. Sidorov, B.A. Baum, V.S. Gushin, Izveztiya VUZov. Chernaya Metallurgiya, 10, 155 (1984) (in Russian). 